\title{
The Three Sisyphean Tasks of Archaeology
}

\author{
Leif Gren
}

\begin{abstract}
This paper deals with research-history of archaeology and how the constant problem has been how to draw lines in a blurred continuum. The only way to deal with the problem is to find a general human point of departure, regardless of time and space.
\end{abstract}

Leif Gren, Riksantikvarieämbetet, Fr-syd, Lantmäteriet,

Box 524, S-37l 23 Karlskrona, Sweden.

\section{INTRODUCTION}

From Homer and Greek mythology we remember the touching story about Sisyphus, king of Corinth, who managed to acquire great fortunes, and who was so clever that he even succeeded in tempting Death. But such human recalcitrance could not evade the wrath of the gods, and as punishment Sisyphus was

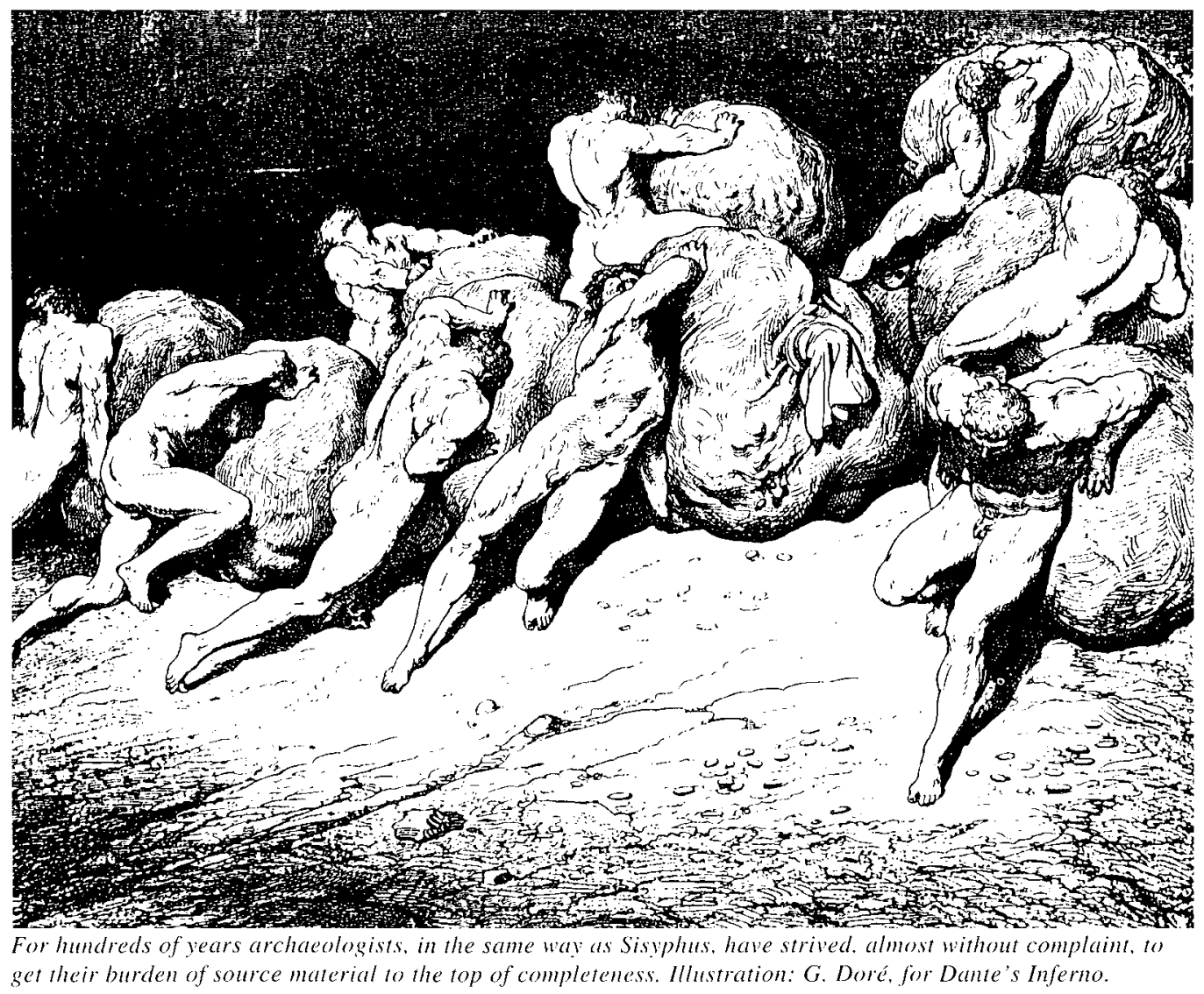


sentenced to an eternal task in the infernal regions. We can hear Odysseus in the eleventh book describe his view of Sisyphus:

"Then I witnessed the torture of Sisyphus, as he wrestled with a huge rock with both hands. Bracing himself and thrusting with hands and feet he pushed the boulder uphill to the top. But every time, as he was about to send it toppling over the crest, its sheer weight turned it back, and once again towards the plain the pitiless rock rolled down. So once more he had to wrestle with the thing and push it up, while the sweat poured from his limbs and the dust rose high above his head."

A never-ending task is well-known to many, also in archaeology. If archaeology is to be something more than purely subjective opinions, it is necessary to find some way of evaluating different statements. All statements about the past are not equally trustworthy. The reference and answer is what we call archaeological source material. Source material is the Sisyphean burden of archaeology.

\section{THE FIRST SISYPHEAN TASK}

For hundreds of years closet scholars repeated what others had already said. In the seventeenth century new knowledge about ancient times was not produced until one went outdoor. The source material of early archaeology was primarily of three different kinds: ancient language terms, portable ancient objects and ancient monuments. From the very beginning archaeologists realised that, in principle, the amount of source material was finite. It turned out to be a natural ambition to gather all ancient things, either as portable objects or as documentation of monuments in the field. The first archaeological scholars, or "antiquarians", set about working at documentation with the greatest enthusiasm.

The first Swedish antiquarian, Johannes Bureus, intended among other things to publish every runestone in Sweden, and in 1624 he published a small collection of woodcuts. One drew up lists of a lot of things one planned to collect (Schück 1932:143), and soon a great number of runestones, ancient castle ruins and churches, gravestones, medieval manuscripts, coins, etc. were recorded. Furthermore one prepared dictionaries of ancient words. During this work knowledge increased and concepts had to be more closely defined as new classes of objects emerged.

There was seldom any doubt that the task of documentation could be finished. For instance one of the scholars, Laurentius Bureus, was very optimistic about the possibility of publishing an etymological lexicon of all ancient Swedish words: "this aforesaid lexicon is a necessary product, and could, I suppose, be completed in a few months" (Schück 1932:183). Johan Hadorph, who was the foremost antiquarian and field surveyor, intended in 1670 to resume the work of Johannes Bureus, and publish all Swedish runestones in a "corpus" that would be superior to a similar Danish study. Hadorph's successor, Johan Peringskiöld the elder, intended to intensify the fieldsurveys and include every kind of ancient monument. A series of books, he said, ought to be published as soon as possible "before the occasional outstanding monument is destroyed and vanishes with us" (Schück 1935:160).

Unfortunately these high ambitions could not be realized. The lexicon came to a standstill already at the letter "A". Bureus' and Hadorph's great project "Monumenta runica" soon proved to be far more extensive than anyone had realized, and in spite of tremendous efforts, only a provisional collection of woodcuts could be published in 1750. The antiquarian production of Peringskiöld was even more unfinished, and only two districts of Uppland appeared in print in 1710 and 1719. In any case the reluctant Sisyphean burden of archaeology had moved a considerable distance uphill.

The fieldsurveys of ancient monuments soon stopped, and it was not until the end of the eighteenth century that work was resumed. 
Private sponsors initiated documentation, and in the early nineteenth century the government granted money for the same purpose. In 1938 when the government decided that all ancient monuments should be registered and marked on official maps, Peringskiöld's dream was rekindled. In the meantime archaeological excavations had greatly increased the amount of source material.

\section{THE SECOND SISYPHEAN TASK}

Archives and maps were filled with the documentation of all kinds of ancient objects and monuments. Some fragments of the great burden escaped on the way, and had to be gathered in new fieldsurveys. In the 1960s and 1970s we had almost reached the top, but some fragments were still missing.

But now something happened that was not supposed to happen! Our Sisyphean burden started to slip, and without resistance it rolled back from the top of completeness. The burden was shown to consist only of objects; what was missing was environments. Our task had been to move objects of culture. Now we had to resume our work and move environments of culture. How, then, is the difference between objects and environments to be understood?

In order to describe something we have to use a language, which employs certain terms for certain objects, one term corresponding, so to speak, to a certain species of objects. To make this possible it is necessary to distinguish between two concepts that we recognize from mathematics, the discrete and the continuous.

The discrete is always sharply delimited, i.e. sharp. Our language and our sense of logic is thus always discrete and consequently our methods of documentation are always discrete. The continuous, on the other hand, lacks sharp limits and gradually turns into something else, i.e. it is blurred (Gren 1990a). In a complete continuum there are no specific transitional parts since everything is a gradual transition.
We may imagine that we are observing a place with traces from ancient times. We are seeing objects. In most cases it is not difficult to delimit the objects, even though it has to be emphasized that objects without a limit do not exist. In the example we can, for instance, count graves, runestones and stone fences since they can easily be apprehended as objects. When one has decided what to register, i.e. how to draw boundaries and delimit objects, then the documentation itself presents no problems. In that case both our language and the objects are discrete. This Bureus and Hadorph realized perfectly well, though they used other words for the same thing.

The first archaeological problem, or Sisyphean task, could be described as the registration of discrete objects and, what was left to be understood, a discrete environment. The objects were specified, but the environment was confined to a specification of the parish the object was situated in. Thus both the objects and the environment were classified discretely. We can describe the constituent parts of the first burden in the following manner:

Archaeological Sisyphean burden no 1: discrete objects - discrete environment

It becomes immediately more difficult when we try to place the objects in relation to each other. In observations of an ancient cemetery the spatial context of the objects must be of some importance. Every object has to be described according to its relationship with other objects. But there are innumerable ways of making this description. How, for instance, is "proximity", "arrangement of groups" or "context" defined? Consequently we have to make definitions of how to transform the continuous environment into some kind of discrete objects. Archaeological research awakened to a "realization of environment", and the old burden could reasonably well be moved again.

Archaeological Sisyphean burden no 2: discrete objects - continuous environment 


\section{THE THIRD SISYPHEAN TASK}

But the gods do not show mercy that easily! If we, for instance, put the objects in the cemetery in relation to something in the environment that is not an object, the problem will be much more severe. A grave mound can be situated on a mountain and a runestone can be situated on the shore. In this case the mountain and the shore are adjuncts, that is, environments of the objects. How can we possibly draw boundaries within the mountain and the shore in such a manner that they can be registered with a necessary discrete language? We have to resort to simplifications, rejecting such things as direction, kind of environment element, etc. The environment has to be transformed into some kind of object.

This problem, however, is not essentially different from the preceding one in which the environment was composed of discrete objects. Now it may prove to be the case that even the very first object can "dissolve" into a continuum. If we leave our ancient cemetery, and follow the stone fences into the forest, perhaps we will reach "areas with clearance cairns", "areas cleared from stones" and "terraces". Now our great Sisyphean burden seems once more to be heavier and striving downwards. When we discover that the soil is "unnaturally disturbed" and that the natural mineral soil is more or less transformed into "artificial humus-rich soil", then our burden becomes overwhelmingly heavy, and begins rolling down.

Archaeological Sisyphean burden no 3: continuous objects - continuous environment

\section{CONCLUSION}

The archaeological burden of source material has just been described as more hopeless than ever. This, however, was not the intention, since archaeology ought to be a joyous science. Nothing is more shameful than being a kill-joy! But in spite of this, nothing comes out of nothing, as Lucretius says, and without an archaeological source material we would not know anything whatsoever about ancient times. Three times, during three hundred years, we have tried to move the burden of source material towards the top of completeness, and we have failed. Not because of idleness but due to the contradiction between our language and reality. The human language is discrete, whereas reality is continuous.

Hold on, what does this mean?! It is in fact ancient human beings, not reality in "itself", that we try to get to know. At last our burden may become lighter - the logical limitation of our existence is identical to that of ancient people. Ancient man, like us, intentionally had to import boundaries and limits into everything to make it discernible as "something at all".

Thus the archaeological source material can only be composed of the intentions of ancient man and nothing else. Objects "in themselves" have to be transformed into objects "for someone". If this is not accomplished we will not be able to move our Sisyphean burden a third time. The old proverb "tertium non datur" - no third chance is also valid in this context, since our sense of logic is unable to deal with a continuum without transforming it into something discrete. Consequently we have to attain some kind of discrete burden of source material.

All archaeological registration must be preceded by the question: could this boundary or limitation, directly or indirectly, be of original intention? Usually this question has remained implicit. But in order to understand what could possibly be the intentions of ancient man, it is necessary to understand in general how the concepts of man are made (Gren 1990b). In this way it would be possible to obtain a burden of source material that, like the first one, is free from built-in logical contradictions. We should act as if the source material consisted of some of the intentions of ancient man, and intentions are always discrete. If we had a totally discrete burden we could perhaps regain the joy and enthusiasm 
of the first generations of archaeological scholars.

If we do not know ourselves, we will not be able to understand either living or ancient people. But we should not be frightened by the thought that we will never succeed in carrying the burden all the way up the hill, and still less by the thought that we can not make

\section{REFERENCES}

Gren, L. 1990a. Människan som en del av landskapet. META 90 1-2. Lund.

- 1990b. Vad är arkeologins mest grundläggande problem? Fornuännen.

Homer. The Odysey. Translation by E.V. Rieu. revised by D.C.H. Rieu. Harmondsworth 1991. it stop there. Nevertheless we have to work as if it was possible (cf. Malmer 1984). The task of getting to know man will certainly never be completed, even if we exert ourselves to the utmost.

English revised by Jacqueline Taffinder.

Malmer, M.P. 1984. Arkeologisk positivism. Fornvämnen. Schück, H. 1932-1935. Kgl. Vitterhets Historie och Antikvitets Akademien. Dess historia och forhistoria. Stockholm. 
